\title{
A educação da mãe carinhosa e o discurso das práticas corporais e esportiva nas páginas da Pais \& Filhos
}

\author{
Maria Simone Vione Schwengber*
}

\begin{abstract}
Resumo: O presente artigo é parte de uma pesquisa inspirada nos campos dos Estudos de Gênero e dos Estudos Culturais que se aproximam das teorizações pós-estruturalistas de Michel Foucault (1988; 1997). Nele discuto a emergência de uma lógica segundo a qual a educação dos corpos, de modo geral, e o das mulheres, de forma específica, se intensifica, a partir do século XVIII. Tem-se definido esse processo educativo contemporâneo mais amplo como "politização do feminino e da maternidade" (MEYER, 2003), um processo que, por extensão, inclui a "politização do corpo grávido" (SCHWENGBER, 2006). Para fazer essa discussão, examinei a revista Pai \& Filhos, no período de 1968 a 2004, utilizando das estratégias metodológicas da análise de discurso. Do resultado das análises, focalizo um movimento que permite visualizar a emergência de uma lógica, segundo a qual a educação dos corpos grávidos se intensifica, por meio das práticas corporais, construindo diferentes posições de sujeito: a de mãe esportiva (que cuida e se cuida); a que abriga e protege; a carinhosa e protetora, responsável pelo filho perfeito.
\end{abstract}

Palavras-chave: Corpo humano. Identidade de gênero. Gestantes. Meios de comunicação de massa.

\section{INTRODUÇÃO}

A sociedade moderna, para Foucault (1999), é demarcada pelo investimento educativo nos corpos. Foucault (1999) mostra que o corpo é um elemento de apoio e articulação para os mais diversos projetos políticos, dotado de grande instrumentalidade nas relações de poder. Foucault (1999), caracteriza o fim do século XVIII como

\footnotetext{
* Doutora em Educação. Professora no Curso de Educação Física do Departamento de Pedagogia da Universidade Regional do Noroeste do Estado do Rio Grande do Sul - UNIJUÍ. Membro do Grupo Paidotribus e participante do Grupo de Estudos de Educação e Relações de Gênero e de Sexualidade - GEERGE -, vinculado ao PPG-EDU da UFRGS.
} 


\section{Artifor Originais}

o momento em que a preocupação com os corpos do indivíduo e da população se dá de forma privilegiada. De modo que para a população, a materialidade dos corpos, é tomada por uma atuação positiva. "Positiva, aqui, não quer dizer menos dolorosa, mas que em vez de anular o corpo, colocou-se sob exposição de condições que potencializariam suas forças" em temos econômico e político (GHIRALDELLI, 2008, p. 99).

Dessa forma, passam a ser objetos de regulação e de controle do Estado as condições de vida, a saúde, o vigor dos corpos, o imperativo da reprodução saudável da espécie e seu próprio "melhoramento", os estados de saúde, longevidade da vida, a fecundidade, a natalidade, a expansão das políticas de regulação da natalidade e da diminuição dos índices de mortalidade - sobretudo da mortalidade infantil. Passa a pensar, então, principalmente, em "política(s) sobre o corpo(s)", ou ainda em "políticas de saúde", expressões pensadas por Foucault (1979) e presentes na contemporaneidade, tal a propriedade dos seus significados.

Nessa direção, organizam-se as "políticas de saúde" através das quais as populações podem ser conhecidas, vigiadas e cuidadas (FOUCAULT, 1979). A partir dessa organização, a saúde das populações firmar-se-ia como um elemento definidor de potencialidades concretas de riqueza dos Estados-Nação, de modo que os corpos assumiram "uma significação diferente; não mais supliciados, mas passam a ser (re)formados, corrigidos, aqueles que receberiam aptidões, um certo número de qualidades" (FOUCAULT, 1979, p. 119). Para Soares (2006, p. 75), gerir a população significa "gerir a população em profundidade, minuciosamente, no detalhe", [...] gerir e controlar os corpos utilizá-los ao máximo [...] majorá-los "como efeito útil a dimensão corporal".

É evidente que o pressuposto de que a riqueza dos EstadosNação se mede pela saúde dos corpos de seus habitantes afetou, de alguma forma, quase todos os corpos, como afirma Foucault (1999). Tomo esse pressuposto do autor para complementá-lo que afetou (e afeta), de modo particular, os corpos das mulheres, em razão de sua capacidade ímpar de gestar e parir a vida.

Movimento, Porto Alegre, v. 15, n. 03, p. 209-232, julho/setembro de 2009. 
É na confluência desse discurso do Estado e das Nações que decorre a mudança de posicionamento em relação às mulheres (seus corpos), consideradas, a partir daí, como corresponsáveis pelo crescimento e pela potência das Nações. A mulher passa a ser vista como fundamental para o desenvolvimento do Estado, na razão direta da prosperidade da família (COSTA, 1979). Nesse contexto, as mulheres (seus corpos) foram investidas de uma "nova" função política no seio da família, responsáveis pela criação de filhos sadios moral e fisicamente. O século XIX presencia a institucionalização dos saberes, sobretudo, do saber médico acerca dos corpos das mulheres. Em termos históricos, identifica-se um fenômeno: o da "ortopedia" do corpo feminino (FOUCAULT, 1999, p. 97) do corpo que ameaça não só a estabilidade como também a saúde econômica da Nação. Nessa perspectiva, entende-se que os corpos, particularmente os das mulheres e das crianças, necessitam de ser acompanhados em seus níveis de saúde, para evitar o comprometimento da força do Estado, da ordem urbana e dos resultados de um capitalismo em pleno vapor.

O investimento no corpo das mulheres e no das crianças como forças produtivas surge, então, como certa garantia de prosperidade nacional (FELIPE, 2003). A preocupação com corpos reprodutivos representou uma novidade no sentido de que: "[...] é a primeira vez que, pelo menos de uma forma constante, uma sociedade afirma que seu futuro e sua fortuna estão ligados, a produzir um número de cidadãos, mais qualificado em termos biológicos" (FOUCAULT, 1999, p. 28).

Esse "apelo" foi gradativamente incorporado, no imaginário cultural feminino, já que permitia às mulheres alcançar um status social valorizado: tornavam-se necessárias à sociedade, através de seus corpos e do trabalho reprodutivo, com consequente valorização da posição a de "[...] ser uma boa mãe, uma mãe cuidadosa [...] como condição para ser uma mulher feliz e respeitada" (BADINTER, 1985, p. 147), essa era uma das fortes mensagens propagadas.

Embora essa transição tenha sido longa e lenta, heterogênea e variável, conforme a classe social, as mulheres burguesas foram as

${ }^{1} \operatorname{ort}(\mathrm{o})$ - reto

Movimento, Porto Alegre, v. 15, n. 03, p. 209-232, julho/setembro de 2009. 


\section{Artigor Originais}

primeiras a incorporarem em suas vidas os novos ensinamentos corporais; já as aristocratas e as pobres foram as últimas a assimilarem em seus hábitos o novo perfil materno - de cuidar-se na gravidez (CORRÊA, 2001).

Para Badinter (1985), nesse contexto, reorganiza-se uma "economia da vida", uma gestão técnico-administrativa da vida, por meio de políticas sobre os corpos (ventres), efetivadas de muitas formas, na literatura e na arte, nos tratados médicos, nas imagens anatômicas e nos discursos das diferentes áreas da saúde, da Medicina à Educação Física.

Entendo que tais discursos me remetam à "invenção do corpo grávido" e associam os corpos grávidos a uma rede de práticas e de saberes, tais como cuidados pré-natal, cursos especializados, consultas médicas, academias, alimentos diferenciados. A esse movimento chamo de politização da maternidade e do corpo grávido, “[...] não no sentido de inovadora, mas no sentido de uma atualização, exacerbação, complexificação e multiplicação de investimentos educativoassistenciais" (MEYER, 2006, p. 47) que objetivam maximizar, através da saúde materna, a saúde do feto.

$\mathrm{Na}$ medida em que a reprodução saiu da esfera doméstica e familiar, tornou-se mais regulada e vigiada, reforçando a centralidade da mulher no processo da gestação, no ato de parir, aleitar, cuidar e educar os filhotes até a respectiva independência.

Esses discursos de ser mãe cuidadosa, cada vez mais complexos e amplamente produzidos e divulgados em diversos artefatos da cultura como poemas, canções, romances literários, filmes, novelas, documentários e, também, pelas diferentes ciências, mídias e propagandas, produziram algo novo: saberes que passam a ditar prescrições, normas sobre os modos de cuidar dos corpos femininos, cujo ponto de partida foi a formulação de regras e técnicas para gerir e produzir os corpos mais saudáveis possíveis. O binômio saber-poder entendido também como técnicas de procedimentos "prescritos aos indivíduos para fixar sua identidade, mantê-la ou transfor-má-la [...] graças ao conhecimento de si por si” (FOUCAULT, 1999, p. 109).

Movimento, Porto Alegre, v. 15, n. 03, p. 209-232, julho/setembro de 2009. 
Para Foucault (2004), esses saberes, com suas prescrições, não educam apenas os corpos, mas produzem subjetividades principalmente, pelo incitamento e encadeamento de posições e identidades. Foucault descreve que os saberes agem na constituição dos sujeitos, produzindo determinadas identidades. ${ }^{2}$ Por isso, para o autor, não existe um sujeito universal; ao contrário, o sujeito produzido é historicamente pelos diferentes modos de subjetivação, sendo que esses modos variam em conformidade aos diferentes momentos históricos e sociais da sociedade. Subjetivação, assim, entendida por Foucault como processo de constituição dos sujeitos.

Para Foucault Vigarello (2001) e Soares (2006), a história do corpo (da primitiva à pós-moderna), inclusive a dos corpos grávidos, é um pouco a história de saberes; é uma história heterogênea e plural. Há uma constante atualização e multiplicações de saberes assim como " [...] há um incremento racional sempre intenso e extenso nos modos de intervir nos corpos grávidos, medindo a cada dia mais intensiva e progressivamente todas as suas funções e quase toda sua expressão".

Dentro desse contexto de (educação e) reinvenção dos corpos grávidos é que as práticas corporais e esportivas encontram seu espaço. Como destaca Soares (2006), as práticas corporais e esportivas contemporâneas não ficaram fora dessa rede educativa, são "pedagogias virtuosas", que não se restringem apenas a dar contornos físicos e promover habilidades aos corpos das gestantes, mas, sobretudo, interferem nos modos delas serem mães, produzem identidades. Isso significa dizer que as práticas corporais e esportivas afirmam-se como fundamentais nos processos de produções identitárias (SOARES, 2006) e intervêm no processo de constituição dos sujeitos.

Procuro mostrar neste artigo como e de que modo as práticas corporais e esportivas nos educam como sujeitos de gênero, nos ensinam a conferir sentido, no caso, à gravidez e à maternidade, num processo nunca acabado e completo, como observa Meyer (2003).

\footnotetext{
2 Identidade(s) não tomada aqui como individualidade nem como um processo estático (e definido), mas como processo aberto, que envolve uma incessante reorganização de significados culturais com os quais nos relacionamos nos contextos socioculturais. Assim entendemos as identidades como múltiplas e plurais, portanto, passíveis de ser assumidas, ao mesmo tempo, pelos mesmos ou por diferentes atores sociais (SILVA, 2001).
}

Movimento, Porto Alegre, v. 15, n. 03, p. 209-232, julho/setembro de 2009. 


\section{Astifor Originais}

Maria Simone Vione Schwengber

\section{AEDUCAÇÃO ESPORTIVA DOS CORPOR GRÁVIDOS: NA REVISTA PAIS \& FILHOS}

Fazendo um pequeno mergulho na cultura ocidental, posso perceber uma opção preferencial pelas práticas esportivas. ${ }^{3}$ Parece que as práticas esportivas, de um modo geral, concorrem e se associam à ideia de aperfeiçoamento dos corpos, de sucesso e de superação dos limites, por meio de um trabalho exaustivo de repetição de gestos motores, como destaca Soares (2006). As práticas corporais e esportivas compõem-se como importantes técnicas de regulação da vida contemporânea, encarnam o paradigma de um certo rendimento, pois o esportista não se forma sem um treinamento profundo de seu corpo. Nessa direção, para o esportista existir, é preciso que ele treine o corpo, de modo específico e singular.

Pode-se pensar então a produção social do corpo da gestante esportiva nas páginas da Pais \& Filhos a partir da metáfora da fabricação dos gestos:

[...] corrigiram-se aos poucos as posturas; uma coação calculada percorre cada parte do corpo, se assenhoreia dele, dobra o conjunto, torna-o perpetuamente disponível e se prolonga, cria-se o hábito, em resumo, cria-se o senso de responsabilidade com a instauração de um conjunto de comportamentos (FOUCAULT, 1999, p. 25).

O corpo da gestante "[...] torna-se assim em algo que se fabrica, de uma massa informe, de um corpo inapto" (FOUCAULT, 1999, p. 25), faz-se uma gestante esportiva, disciplinada, cuidadosa.

Para Soares (2006, p. 86), o esporte moderno desenha e exibe um mundo de corpos perfeitos; é um espaço de perfeição " [...] o esporte é construído na dinâmica própria da sociedade industrial; encarna e expressa não só comportamentos desejados, mas também se revela como um divertimento consentido". A imagem da gestante

\footnotetext{
${ }^{3}$ Para Soares (2006) é possível localizar na cultura contemporânea várias denominações, tais como: voga esportiva, estilo de vida esportiva, versão atlética esportiva, versão muscular da vida contemporânea e culto da performance.

Movimento, Porto Alegre, v. 15, n. 03, p. 209-232, julho/setembro de 2009.
} 
esportiva, nas páginas da Pais \& Filhos, me parece curiosa, por se constituir numa espécie de ícone da mulher cuidadosa, disciplinada. O esporte na cultura contemporânea apresenta uma lógica interna, isto é, valores, normas, regras; formas de exercício, e, principalmente, de controle do corpo.

É importante destacar que as práticas esportivas na contemporaneidade elegeram a mídia como espaço privilegiado de enunciação; destaca-se e ou se enuncia às práticas esportivas como um modo de cuidado de si e como um ponto de partida de um projeto aperfeiçoamento infinito dos corpos. De modo que as mulheres contemporâneas começam a apostar, a se interessar pelo aperfeiçoamento corporal, inclusive as grávidas, como essa pesquisa mostrou. Rosa Fischer (2005) é uma das estudiosas que chama a atenção para a importância que a mídia assume, ocupando uma posição central no processo de constituição do sujeito contemporâneo, nos modos de ser homem e mulher, inclusive nos de ser pai, mãe e gestante.

Observa-se, hoje em dia, uma frutífera aliança entre a educação dos corpos e a mídia. Para Vaz (2006, p. 8), a forma de poder predominante, agora, não é mais a vigilância dos corpos, mas a informação que adverte os indivíduos "dos riscos, dado o que fazem e o que trazem como herança". Posso dizer que a contemporaneidade monitora os corpos através das informações, dentro daquilo que Fraga (2005, p. 28) chamou de uma "biopolítica informacional" - "[...] uma forma de governo que não depende (apenas) da relação-corpo-a-corpo para fazer valer um poder sobre a vida da espécie, mas de um conjunto de técnicas, procedimentos e saberes que regulam a vida" por meio das informações.

Essas considerações me instigaram a buscar compreender como um artefato específico da mídia brasileira, a Pais \& Filhos, ${ }^{4}$ contribuiu para a reprodução e veiculação do discurso enaltecedor das

\footnotetext{
${ }^{4}$ A Pais \& Filhos foi publicada pela Editora Bloch; atualmente, é a Manchete que a edita. A escolha por essa revista deve-se, primeiramente, ao fato de ela ser uma publicação midiática de ampla circulação no Brasil, reconhecidamente privilegiada, por seu tempo de permanência no mercado frente a outras publicações destinadas ao mesmo segmento. Ela surgiu em setembro de $1968 \mathrm{e}$ mantém-se até hoje no mercado brasileiro sendo, portanto, a mais antiga nesse gênero.
}

Wovimento, Porto Alegre, v. 15, n. 03, p. 209-232, julho/setembro de 2009. 


\section{Antifos Origimais}

práticas corporais e esportivas, na contemporaneidade. No contexto da mídia brasileira direcionada à família e, sobretudo, às mulheres (potencialmente) mães, ressalto a importância da Pais \& Filhos, uma vez que essa publicação é tida como "a mais tradicional revista da família brasileira, há trinta e sete anos no mercado". A revista desfruta de uma longevidade notável, comparada com a quanti-dade considerável de séries de revistas lançadas, para esse público, a cada ano no Brasil ${ }^{5}$; ainda mais que poucas delas conseguem passar pela prova dos dez anos da primeira publicação.

Segundo Mira (2001), a Pais \& Filhos é identificada como a primeira publicação brasileira (1968) a discutir a educação dos filhos, a mostrar a necessidade de pais e mães planejarem a chegada de seus/suas filhos/as, sendo que, das revistas destinadas a pais e mães, é a revista brasileira de maior tiragem e é considerada como uma das publicações mais lidas por esse segmento da população.

Diante disso seduziu-me a ideia de compreender: como o discurso das práticas corporais e esportivas, na Pais \& Filhos, serve ao objetivo de regular e governar os corpos grávidos? Como tal discurso produz identidades materna, na contemporaneidade?

Para respondê-las, examino exemplares da Revista Pais \& Filhos, publicados no período de 1968 a 2005, apoiando-nos na perspectiva dos Estudos de Gênero e dos Estudos Culturais que se aproximam das teorizações pós-estruturalistas e utilizando como estratégia metodológica a análise de discurso foucaultiana.

Do ponto de vista da metodologia adotada, realizei as análises valendo-me das contribuições de Foucault no que tange ao conceito de discurso e enunciado. Foucault sugere que o(a) pesquisador(a) tome os discursos, em sua materialidade, e tencione suas condições de produção, e as posições de sujeito neles descritas.

Instrumentalizada por esse "modo de ver", optei por mapear os enunciados nos discursos da Pais \& Filhos, partindo das observações de regularidades, insistências e repetições. Segundo Foucault,

\footnotetext{
${ }^{5}$ Destaco aqui algumas das revistas brasileiras: Gravidez Feliz, Gravidez Especial, Gravidez e Gestação, Supermãe, Da Concepção ao Nascimento, A Gestação, Ser Mãe Especial, Seu filho e Você, Crescer em Família.

Movimento, Porto Alegre, v. 15, n. 03, p. 209-232, julho/setembro de 2009.
} 
um enunciado comporta duas dimensões: uma dizível e outra visível. Assim, analisei os discursos e as imagens que integram, frequentemente, os textos da Pais \& Filhos, não como peças ilustrativas, mas como práticas discursivas. Soares e Goellner (2004) ensinam que as imagens não são independentes, pois estão ligadas a determinados regimes de poder e movimentam significados, induzindo o(a) leitor(a) a visualizar (focalizar) certas coisas em detrimento de outras.

\section{A MÃE MODERNA E A MÃE ESPORTIVA}

A partir da primeira década de existência (1968-1978), observei, na Pais \& Filhos, uma rede mais ampla de cuidados, de novos saberes, que passam a ser destacados como fundamentais a um "bom" pré-natal. Como se vê, são muitas as intervenções e os discursos destinados a educar os corpos grávidos, de modo que as práticas corporais esportivas, como exemplo de práticas contemporâneas, não ficam fora dessa rede educativa. Na segunda edição da Pais \& Filhos, já encontrei a primeira prescrição de exercícios físicos para gestantes, traduzida nesta representação:

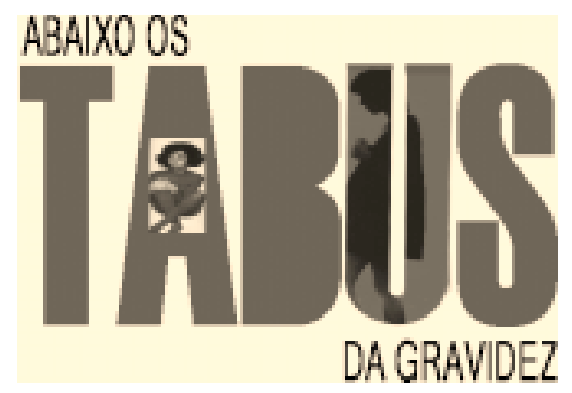

Figura 1. Estúdio $P \& F$.

Pais \& Filhos, São Paulo, n. 64, p. 18, fev. 1974.

Abaixo os Tabus da Gravidez... exercícios na gravidez.

Exercícios físicos, sim. (PAIS \& FILHOS, 1974, p. 66).

A revista faz, inicialmente, um claro esforço para combater os "ditos" tabus afirmando que os exercícios físicos "não são proibidos,

Movimento, Porto Alegre, v. 15, n. 03, p. 209-232, julho/setembro de 2009. 
nem perigosos, nem considerados impuros". Essa chamada evoca um corpo com roupa esportiva, cabelos curtos, olhos marcados pela maquiagem (ou seja, toalete sofisticada, mesmo que esportiva) que colaboram para marcar os traços modernos e fortes da gestante. Era impensável, no contexto de 68, em que emergia a revista, aspirar a ser moderna: sem cortar o cabelo, sem recorrer à maquiagem e ao uso de roupas e práticas esportivas. A Pais \& Filhos investe na produção da nova mulher: moderna, uma mãe pra frente, ágil e capaz de enfrentar os desafios, inclusive superar alguns tabus, dentre os quais a ideia do desprezo do exercício físico à grávida.

Na realidade, a associação entre as ideias de esporte e modernidade não eram novas em 1968, quando emergiu a Pais \& Filhos. Schpun (1999, p. 122), em seus estudos sobre o esporte no contexto cultural de São Paulo do século XIX, identifica que "os primórdios do esporte no Brasil estão ligados a um momento histórico da modernidade em que o País, recém-independente, começou a construir um projeto de nacionalidade, buscando formas 'modernas' de ser dos países desenvolvidos".

Avançando um pouco mais, Schpun (1999) identificou no esporte um elemento da expressão da modernidade, inclusive, associando-o à mulher. A literatura brasileira apresenta visões diversas dos indicativos da expansão das práticas esportivas para as mulheres, no caso, para as mulheres gestantes. Apesar disso, foi apenas a partir da década de trinta (da aceleração da modernização social ocorrida) que temos evidências ${ }^{6}$ do aumento da prática esportiva feminina em nosso País, inclusive, para o contingente de mulheres grávidas (GOLLNER, 2003).

O século XX testemunhou uma ampla popularização do esporte, uma enorme penetrabilidade social. A capacidade de mobilização

\footnotetext{
${ }^{6}$ Estas evidências vão da inserção das mulheres nos clubes esportivos, passando pelo crescente número de competições específicas para as mulheres até a participação feminina brasileira em Jogos Olímpicos, que se iniciou em 1932, com a participação solitária de Maria Lenk na natação, e que, em 1936, em Berlim, já havia crescido para seis competidoras. Para Schpun (1999, p. 122) os Jogos Femininos do Estado de São Paulo demonstram que, na década de 30, era ainda uma prática bem mais aceita e frequente entre as jovens e mulheres das famílias de origem europeia, especialmente alemã.

Movimento, Porto Alegre, v. 15, n. 03, p. 209-232, julho/setembro de 2009.
} 
popular pelo esporte permitiu que fossem estabelecidas interfaces com dimensões da vida social que transitam desde a saúde até a economia e a política, passando pelos conflitos de ordem racial e étnica. No entanto, é a partir das primeiras décadas do século XX que a participação das mulheres se amplia, adquirindo, portanto, maior visibilidade. $\mathrm{O}$ desenvolvimento industrial, as novas tecnologias, a urbanização das cidades, a mão de obra imigrante, o fortalecimento do Estado, as manifestações operárias e os movimentos grevistas, sobretudo o movimento feminista, cujas militantes lutaram pela experimentação de prazeres dos sentidos corporais e de novas possibilidades culturais. E, nessa perspectiva, as práticas corporais e esportivas se inserem de modo mais alargado no contexto social. Essas inúmeras articulações e diálogos do esporte com outras esferas da vida materializam um pressuposto que me parece fundamental para uma reflexão acerca desse fenômeno: há uma profunda correspondência entre esporte e sociedade(s) (DAIOLO, 2004). Existe, portanto, uma inexorável ligação entre a maneira como as práticas corporais e esportivas se manifestam e os valores culturais da sociedade que as praticam.

É importante destacar que o corpo esportista constitui um polo central de referência das identidades de mulheres e de homens contemporâneos. Para Lipovetsky (2006), a sociedade contemporânea passou a ser cada vez mais dependente das proezas das tecnociências, e assim confiamos e apostamos em práticas que prometem corpos superpotentes, autossuficientes e ativos. Entendo que é nessa direção que esse ordenamento desloca um outro olhar sobre a energia física das mulheres. Essa supremacia de aperfeiçoamento está ligada ao que Schpun (1999) denominou a "prova da modernidade", à necessidade de mostrar certos padrões de aperfeiçoamento, inclusive, no plano corporal. Observamos a erupção de uma cultura apoiada nos ideais de superação de si. O ideal de superar-se e de vencer, de aumentar as capacidades, invadem a sociedade contemporânea em seu conjunto, absorvendo os modos de existência, a intimidade e tantas outras instâncias. Para Lipovetsky (2006, p. 261) a cultura do desempenho explode em todas as direções "[...] dos estádios à empresa, dos lazeres à escola, da beleza à alimentação, do sexo a saúde, quase todos os domínios são apanhados por uma lógica de concorrência e de aperfeiçoamento [...]".

Movimento, Porto Alegre, v. 15, n. 03, p. 209-232, julho/setembro de 2009. 


\title{
220 Artifor Originais
}

Maria Simone Vione Schwengber

É nesse contexto que o esporte, a partir da sociedade moderna, constitui-se como uma instância pedagógica a produzir corpos "cuja espetacularização se dá seja pela exibição de performances cada vez mais aprimoradas, seja pela construção de corpos comumente identificados como perfeitos, ou ainda pela associação da sua prática com a aquisição de saúde e de beleza" (COLLNER, 2003, p. 1 ).

Soares (2003) instiga-nos a considerar que, nos últimos 200 anos, no mundo ocidental, tem-se (a)firmado "uma cultura do movimento", sustentada pela ciência e pela tecnologia, sobrepondo-se aos indivíduos, aos grupos, às diferentes classes sociais, como prática importante de cuidado que (re)define seus objetivos como "uma prática indispensável à saúde". 7 Como bem observa Carmem Soares (2003, p. 10), parece que hoje em dia há uma tentativa de convencimento "da necessidade imperiosa de colocar o corpo em movimento, sem o que não há saúde".

Entendo que vários acontecimentos e movimentos contribuíram para a afirmação da importância das práticas corporais e esportivas prescritas para as mulheres, inclusive para as gestantes, no século XX. Castells (1999, p. 171-172) destaca quatro movimentos básicos associados:

\begin{abstract}
O primeiro, a transformação da economia e do mercado de trabalho associada à abertura de oportunidades para as mulheres no campo da educação [...].

Em segundo lugar vêm as transformações tecno-lógicas ocorridas na biologia, farmacologia e medicina, que proporcionaram um controle cada vez maior sobre a gravidez e a reprodução humana [...].

Em terceiro, tendo como pano de fundo a transformação econômica e tecnológica, o patriarcalismo foi atingido pelo desenvolvimento do movimento feminista, conseqüência dos movimentos sociais da década de $60[\ldots]$.
\end{abstract}

\begin{abstract}
${ }^{7} \mathrm{O}$ uso desta expressão saúde é retomado porque, como observa Soares, se analisarmos o processo histórico da Educação Física no Brasil, perceberemos que esse tipo de legitimação das práticas corporais é bastante antigo. Soares (1994) afirma que as primeiras tentativas de incluir a educação física no universo escolar foram em nome da promoção da saúde, higiene física e mental, da educação moral e eugênica. A autora acrescenta que o sentido do conceito de saúde não ficou estático, modificando-se de acordo com as condições históricas de possibilidades.
\end{abstract}

Movimento, Porto Alegre, v. 15, n. 03, p. 209-232, julho/setembro de 2009. 
E o quarto elemento é a rápida difusão da cultura urbana, industrializada e globalizada, em um novo mundo interligado, por onde pessoas e experiências passam e se misturam e se propagam [...].

Goellner (2004, p. 362) destaca outros acontecimentos e circunstâncias que ajudaram a reforçar a importância das práticas corporais e esportivas para mulheres, como competições nacionais e internacionais, Olimpíadas, criação de clubes esportivos, programas governamentais e não governamentais, mulheres "que faziam força física em casas de espetáculos, circos e music halls nos Estados Unidos e Europa", proliferação das imagens esportivas da mídia nos cinemas e propagandas, a própria profissionalização do ideário esportivo, os concursos de misses, entre outros acontecimentos.

Entendo que acontecimentos esportivos como os destacados por Goellner (2004) criaram e criam condições de possibilidade para a afirmação, cada vez maior, da prescrição dessas práticas para as mulheres brasileiras, inclusive para as grávidas. Não é à toa que uma variedade dessas práticas para as gestantes eclode com mais força a partir da segunda metade do século XX, ${ }^{8}$ garantindo-se como prática importante de cuidado, pautada pela negação do corpo "real" e pela busca de aprimoramento do corpo grávido e da saúde. À medida que os anos transcorreram, as perspectivas sob as quais se qualificavam as práticas corporais e esportivas para as gestantes foram se alterando, sendo possível identificar, nas últimas décadas, algumas mudanças importantes.

\section{GRAVIDEZ SAUDÁVEL: NEM O EXCESSO NEM A CARÊNCIA DE MOVIMENTOS CORPORAIS}

É importante destacar que o cuidado ideal(izado) na Pais \& Filhos não sugere, inicialmente, nem o excesso nem a carência de movimentos corporais. A revista, nos primeiros dez anos do seu projeto editorial, faz todo um movimento para mostrar que as práticas corporais

${ }^{8} \mathrm{~A}$ ampliação da participação das mulheres nos esportes escolares foi autorizada pelo ConseIho Nacional de Desportos (Brasil 1979, Brasil 1983) e endossada por muitos acontecimentos e estudos científicos que jogavam por terra os argumentos sobre a probabilidade de as mulheres estarem mais propensas às lesões esportivas do que os homens (AZEVEDO, 1988).

Movimento, Porto Alegre, v. 15, n. 03, p. 209-232, julho/setembro de 2009. 
devem ser realizadas/vivenciadas pelas gestantes na justa medida, "com movimentos nem para mais e nem para menos" (PAIS \& FILHOS, 1970, Capa).

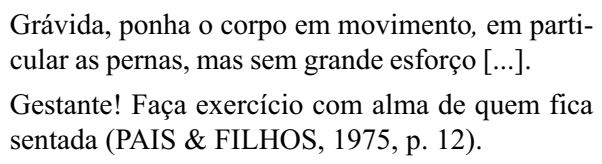

Cuidar do corpo grávido agora implica colocá-lo em movimento (SANT'ANNA, 2001). É importante destacar que, no contexto da Pais \& Filhos, até 1970, se fazia presente a recomendação de cuidados para o corpo muito mais pelo uso de meias de nylon como precaução contra varizes do que pela prática de exercícios físicos. Porém, a partir desse período, na revista, as recomendações de uso das meias se mantiveram, mas acrescidas de prescrições de algumas práticas corporais. As gestantes são estimuladas, pela revista, a assumir e a manter ações dinâmicas; uma representação corporal mais enérgica abre caminho, tornando insuficiente o uso apenas das meias. O repouso é substituído pelo movimento. A revista recomenda às gestantes:

[...] abrirem-se para um trabalho muscular, por meio das prescrições de alguns movimentos para o corpo grávido, com alternâncias: movimento estáticos e dinâmicos (PAIS \& FILHOS, 1975, p. 13).

A regra destacada, então, pela Pais \& Filhos é a de que a gestante deve se movimentar, mas na justa medida; a busca da justa medida é cercada de parâmetros prescritivos. No contexto da cultura ocidental, havia um elaborado sistema de regras prescrevendo que os corpos grávidos podem e devem movimentar-se, ao qual a Pais $\&$ Filhos aderiu, porém, dentro de uma esfera segura. Assim, nos primeiros dez anos do projeto editorial da Pais \& Filhos (19681978), as práticas corporais prescritas/recomendadas/indicadas para gestantes são as práticas alternativas, suaves e brandas, ${ }^{9}$ tidas como uma forma importante de cuidado, distanciando-se do caráter de esforço. De modo que se localizam facilmente excertos como este que segue:

${ }^{9}$ A revista trata as expressões "alternativas", "suaves" e "brandas" como sinônimas. Desse modo, vou me referir ao primeiro termo - práticas corporais alternativas.

Movimento, Porto Alegre, v. 15, n. 03, p. 209-232, julho/setembro de 2009. 
$[\ldots]$ as atividades corporais alternativas e suaves para gestantes são as mais aconselhadas, aliás, as recomendadas (PAIS \& FILHOS, 1970, p. 41).

A Pais \& Filhos formula uma proposta de trabalho corporal que otimiza o preparo do corpo grávido, mas com orientações no sentido de dar preferência às práticas corporais nomeadas e reconhecidas, nesse contexto, como alternativas e suaves. Chamo a atenção, aqui, para o uso do termo "alternativas" para designar essas práticas para as gestantes, porque, sendo a gravidez uma condição particular, que demanda o abrandamento de esforços nas práticas, buscam-se propostas alternativas.

Uma consulta ao dicionário, a esse recurso tão enredado nas "operações de fixação e legitimação dos significados atribuídos às palavras", como diz Meyer (2000, p. 36), permite delimitar algumas das definições do termo "alternativo": "Diz-se daquilo que representa uma opção entre duas ou mais possibilidades."; "Que adota uma posição independente em relação a tendências dominantes." (AURÉLIO, 2000). Percebo que o uso da expressão "alternativas" como adjetivo do substantivo "práticas", passa a representar o movimento que a Pais \& Filhos faz para posicionar as práticas corporais alternativas em polo alternativo ao das práticas esportivas.

As práticas corporais são consideradas "alternativas" pela sua capacidade de garantia de prudência com os corpos grávidos. O próprio adjetivo "suave" aparece no dicionário associado às expressões "delicado", "moderado", "equilibrado" - muito mais positivadas para o feminino e esperadas, sobretudo, de um corpo grávido.

Pode-se explicar o alternativo, no projeto da Pais \& Filhos, evocando-se também os efeitos de uma cultura do movimento feminista, ${ }^{10}$ que, em vias de afirmação, no final da década de 1960 , exigia

${ }^{10}$ É importante destacar que 1975 se torna o Ano Internacional da Mulher, logo estendido por todo o decênio (de 1975 a 1985). Encontros e congressos de mulheres se sucedem, cada qual com sua especificidade de reflexão, assim como a criação de dezenas de organizações, muitas nem tão feministas, mas todas reivindicando maior visibilidade, conscientização política e melhoria nas condições de trabalho das mulheres. O "8 de março" é finalmente declarado Dia Internacional da Mulher, por iniciativa da ONU, e passa a ser comemorado em todo os Países, de forma cada vez mais organizada (SCAVONE, 2004).

Movimento, Porto Alegre, v. 15, n. 03, p. 209-232, julho/setembro de 2009. 
respeito e direitos iguais, militando por alternativas aos corpos, como as de certa liberação sexual, discussões e práticas do amor livre, uso dos contraceptivos, aborto, divórcio (SACAVONE, 2004). A revista funciona um pouco como porta-voz de reivindicações, tais como "nosso corpo nos pertence", que foi um dos grandes motes a recuperar as inflamadas discussões promovidas por feministas e por anarquistas sobre corpo e sexualidade, no início do século XX.

Desse modo, a Pais \& Filhos dissemina uma quantidade de informações sem precedentes, no sentido de reafirmar a importância das práticas de atividades corporais alternativas para as gestantes.

Grávida! Entregue-se às atividades corporais alternativas, suaves e brandas.

Para manter-se saudável e bem disposta durante toda a gestação, nada melhor do que deixar de lado a preguiça e mexer o corpo de um jeito suave e não de forma violenta (PAIS \& FILHOS, 1976, p. 17).

Esse excerto sinaliza o quanto, para a revista, as grávidas necessitam realizar atividades corporais diferenciadas. Entretanto, não posso deixar de pensar nos diversos significados atribuídos à expressão "práticas corporais esportivas", na cultura ocidental, como assinala Soares (2005). Se, de um lado, o esporte faz uma referência ao rendimento extremo, à competitividade máxima e à extrapolação de limites, de outro, associa-se à ideia de um trabalho de aprendizagem do espírito de equipe, cooperação, negociação e mesmo de superação individual (SOARES, 2005). As práticas corporais justificam-se para as gestantes, em princípio, também na esteira dessa perspectiva moral, como oportunidade para interação social mãe e filho. Essas práticas são repolitizadas como metáfora de "cooperação entre os corpos mãe e filho(a)", num contexto em que esse vínculo é um valor moral positivo, como justifica o excerto seguinte:

Nada é mais saudável do que as atividades físicas para melhorar a relação de ambos: mãe e feto (PAIS \& FILHOS, 1976, p. 17).

Triunfa e se populariza na Pais \& Filhos o modelo da mãe cuidadosa - que cuida do outro e se cuida, como do seguinte exercício prescrito:

Movimento, Porto Alegre, v. 15, n. 03, p. 209-232, julho/setembro de 2009. 
Toque na barriga.

Você deve respirar devagar e num ritmo constante, toque, aperte e solte (como se estivesse amassando pão) a barriga, toque afagando-a, toque muito suave e lentamente, toque encostando levemente na pele, toque mais firme (de segurança). Essa técnica pode ser feita também em movimentos circulares (PAIS \& FILHOS, 1976, p. 119).

As práticas alternativas apresentam-se, como se observa no excerto, como um trabalho corporal educativo que caminha na direção de mostrar a gestante se relacionando harmonicamente, com afabilidade, maciez, brandura e curiosidade com seu estado de gravidez. Esse exercício enfatiza, por isso, movimentos contínuos, comedidos, sensíveis, tranquilos, harmoniosos. Para realizá-lo, a mãe age, ordena, acarinha, mima, afaga - mãe representada aqui como aquela que dá assistência, auxilia, aguenta; aquela que não se afasta da interação e, conformando-se com a conduta, abaixa os olhos, junta as mãos e cobre com ternura o(a) filho(a), num ato de espera do que deseja. Um desejo que se realiza com a suavidade no movimento dos dedos, o apelo ao tato, ao toque, à intimidade, o desejo expresso de harmonia, de realizar a fusão mãe-corpo-filho. A ênfase do exercício está na comunicação da mãe consigo e com o outro (feto/embrião), no prazer de enfrentar a si e à gravidez.

Esse exercício acentua-se muito mais na dimensão da comunicação individual com o próprio corpo e com o(a) do(a) filho(a), como se observa na imagem. A comunicação - mãe e filho(a) - passa, nesse sentido, pela experiência de viver: a experiência da relação com "suavidade, delicadeza, produção de si por meio do exercício [...] ao mesmo tempo flexibilidade e rapidez de adaptações (ao estado da gravidez), leveza e mobilidade, trabalho de vínculo com o outro, senso de iniciativa, capacidade de se envolver com outros" [...], como observa Christian Pociello (1995, p. 124).

Familiarizar-se com o corpo e com o estado de gravidez é apontado, pois, como um dos argumentos mais contundentes pela Pais \& Filhos usados para enfatizar os benefícios das práticas alternativas a partir de 1975. Por exemplo, inúmeros exercícios corporais individuais,

Movimento, Porto Alegre, v. 15, n. 03, p. 209-232, julho/setembro de 2009. 
como o que destaco abaixo, têm como foco sensibilizar as gestantes para essa nova condição.

\begin{abstract}
Objetivo: aprender a observar o corpo
[...] sente confortavelmente diante do espelho (de preferência, nua) observe e toque suavemente no rosto, no colo e nos seios, na barriga (demoradamente) e visualize seu útero.

Visualize agora seu bebê e o espaço que ele está ocupando em seu útero, localize a placenta e o cordão umbilical. Devagar, vá imaginando lentamente cada parte do corpinho, cabeça, peito, braços, mãos, dedos, órgãos sexuais, a cor dos cabelos, o formato do nariz e da boca, dos olhos e a cor... sinta seu coraçãozinho e deixe que a energia de amor do seu coração chegue até você.

Esse exercício, o ideal é que dure uns 40 minutos (PAIS \& FILHOS, 1975, p. 12-13).
\end{abstract}

As características principais dos movimentos propostos nesse exercício são o contato, o toque e a escuta. Parece que aqui "ser mãe é desdobrar-se, fibra por fibra, em dedicação", como destaca Coelho Neto. ${ }^{11} \mathrm{O}$ aspecto que quero enfatizar é justamente a participação do discurso das práticas corporais suaves na ressignificação da relação corpo-gestante e também da relação mãe-feto como um dos discursos que educam as gestantes para aceitarem e a entenderem o novo corpo, que se modifica com a gravidez, e a estabelecerem vínculos amorosos com o feto - já representado como um coraçãozinho que pulsa de amor pela mãe. Para o conselho editorial da revista, quanto mais cedo as mulheres aceitam a condição de estarem grávidas, mais rapidamente têm probabilidade de mudar alguns maus hábitos, tais como: beber muito café e refrigerantes, ingerir álcool, ${ }^{12}$ continuar fumando, usar outras drogas. Essas são estratégias de treinamento em que as gestantes são ensinadas a renunciar aos maus vícios e/ou, pelo menos, a reprimi-los na gravidez.

Lupton (1999) destaca que, no contexto de determinadas vertentes da Psicologia do Desenvolvimento Infantil, a gestante deve

\footnotetext{
${ }^{11}$ Fragmento retirado da poesia Ser mãe é padecer num paraíso!

${ }^{12}$ É interessante destacar que a era do consumo acentua a pacificação dos comportamentos, fazendo um movimento para diminuir

Movimento, Porto Alegre, v. 15, n. 03, p. 209-232, julho/setembro de 2009.
} 
passar, durante a gravidez, por "sucessivas e adequadas etapas" para identificar o que é o self e o que é o bebê - reconhecer o bebê como ser autônomo, separado de si e, ao mesmo tempo, ligado a ela pelo desenvolvimento de um forte vínculo afetivo.

Entendo que esses tipos de exercícios físicos sinalizam, também, que o próprio ato de cuidar de uma outra pessoa é um ato gentil, harmonioso, afetuoso que demanda atitude de colaboração, envolvimento, doação, troca e comunicação. Como se observa nos exercícios anteriores (e em grande parte de outros) prescritos pela revista, há a eliminação do esforço físico, do suor e da fadiga, que são substituídos pela busca do contato e vínculo mãe e filho(a). A harmonia e a gentileza da mãe para com o(a) filho(a), comumente vistas pela cultura como habilidades espontâneas das mulheres, são aprendidas ao preço de controle e vigilância, também veiculados pelo discurso das práticas corporais alternativas. Quem diria? Verifica-se que o amor da mãe, comumente visto pela cultura como da natureza das mulheres, é exaustivamente ensinado, também é reforçado na revista por meio do discurso das práticas corporais alternativas.

Nesse tipo de exercício, cuidar de si, na gravidez, implica então envolvimento e dedicação para com o outro. A isso também se vincula a responsabilidade da mãe, fazendo emergir a preocupação com o ser que ela gestou, reforçando a posição de mãe responsável. Essa atividade corporal desafia a gestante a tornar-se íntima do seu corpo e da sua condição, bem como do corpo de seu(sua) filho(a), o que se contrapõe a uma racionalidade fria, abstrata e distante nos modos de relacionamento, dando vazão a uma racionalidade sensível e afetuosa.

A técnica corporal do toque é mostrada pela revista como imprescindível e desejável para dar segurança e estabelecer confiança entre mãe-filho(a). Ensina-se a mãe a ter mais paciência e menos egoísmo com seu corpo e a receber o(a) filho(a) com menos sofrimento. Esse tipo de prática parece ensinar, ainda, que a gravidez é um trabalho de "alianças" na dimensão da intimidade mãe e fillho(a). A distribuição de posição dos corpos de mãe e filho(a), a orientação dos olhares sobre uma relação de visibilidade e exposição permanente, a privacidade

Movimento, Porto Alegre, v. 15, n. 03, p. 209-232, julho/setembro de 2009. 


\section{Artifor Originais}

exposta ao olhar constante e à vigilância contínua são formas de exercício de poder que se realizam aí. Posso dizer que esses exercícios físicos produzem efeitos importantes, fazendo com que as gestantes se voltem para os vínculos de intimidade, de modo que a mãe, muito mais que o pai, é definida pela Pais \& Filhos como muito mais carinhosa e protetora.

É notável a importância que a revista dá às práticas corporais alternativas, no período de 1970 a 1980 , uma vez que o corpo materno tem um lugar/papel central. Desaconselha-se às gestantes a tomarem os sinais do corpo na gravidez como meros indícios que desaparecerão; recomenda-se que reconheçam e investiguem quaisquer sinais e os limites que eles sugerem.

O corpo é um instrumento ou recurso de ação primordial de cuidados na gravidez; simultaneamente, a gestante recebe um grande incentivo para que se autoconstitua, mas não de qualquer forma, e sim de forma comedida, tranquila, docilizada, segura. As práticas alternativas estão inscritas em um imaginário social de liberação do corpo, da sexualidade, dos sentimentos; seus jogos corporais colocam o corpo em destaque, incentivando o sentimento de autonomia, mas, ao mesmo tempo, orientando suas condutas no sentido de produzir a mãe afetuosa, tranquila, comedida, carinhosa.

É interessante observar o quanto a Pais \& Filhos procura identificar as práticas alternativas com práticas inocentes, tranquilas, seguras, que não oferecem riscos, que ajudam a mãe a conquistar um lindo bebê, a saborear uma vitória. No cerne dessas estratégias, está o pressuposto de que a expectativa da chegada de uma criança é suficiente para que a mãe altere sua rotina, por exemplo, adotando uma atividade física regular e ainda reforça a ideia de que o corpo sadio do filho é resultado do trabalho corporal da mãe, da adoção dessas práticas alternativas. Assim, a confirmação da chegada de uma criança passa ser vista como um investimento, em particular, feito pela mãe e não mais, como "acidente de percurso".

É nesse sentido que a revista incita claramente as gestantes a se adequarem a um modelo da mãe carinhosa a cuidar e se cuidar por meio das práticas corporais e esportivas. A revista ensina e instiga a

Movimento, Porto Alegre, v. 15, n. 03, p. 209-232, julho/setembro de 2009. 
gestante a desenvolver "uma nova saúde, mais forte, autoaperfeiçoada, alerta, alegre, firme e mais audaz que todas as saúdes até agora" como destaca Paul Virilio (1998).

As estratégias de governamento propagadas pela revista e enfatizadas, por exemplo, pelo discurso das práticas corporais e esportivas, parecem dizer às gestantes, de muitas e diferentes formas: sejam Donas de si? O que chama a minha atenção é que nunca fomos tão incitadas a sermos donas de nós mesmas, conhecermo-nos, ao mesmo tempo, nunca fomos tão reguladas e controladas na própria ocupação de si.

Education of the caring mother and the discourse of body and sports practices on the pages of Pais \& Filhos magazine.

Abstract: The present article is an integral part of a research inspired in the fields of Gender Studies and Cultural Studies that approximates to post-structuralist theorizations by Michel Foucault (1998; 1997). We discuss the emergence of a logic according to which both body education, in general, and women's body, specifically, has been intensified since the eighteenth century. We have defined this wider contemporary educative process as "politicization of femininity and motherhood" (MEYER, 2003), a process that, in its extension, includes the "politicization of the pregnant body" (SCHWENGBER, 2006). In order to conduct this discussion, we have examined issues of Pais \& FiIhos magazine published from 1968 to 2004, using methodological strategies of discourse analysis. From the analyses resulting from that investigation, we have spotted a movement that allows for the visualization of the emergence of a logic according to which education of pregnant bodies is intensified by means of body practices, thus building different subject positions: a sports mother (the one that takes care of herself and the others), a mother that shelters and protects, a caring and protective mother who is responsible for a perfect child.

Keywords: Human body. Gender identity. Pregnant women. Mass media.

Movimento, Porto Alegre, v. 15, n. 03, p. 209-232, julho/setembro de 2009. 


\begin{tabular}{l}
\hline La Educación de la Madre Cariñosa y el Discur- \\
so de las Prácticas Corporales y Deportiva \\
en las páginas de la Pais \& Filhos \\
Resumen: El presente articulo es parte de una inves- \\
tigación inspirada en los campos de los Estudios de Gé- \\
nero y de los Estudios Culturales que se aproximan de \\
las teorizaciones pós-estructuralistas de Michel Foucault \\
(1988; 1997). En el discutimos la emergencia de una \\
lógica, según la cual la educación de los cuerpos de \\
modo general, y el de las mujeres de forma específica, \\
se intensifica, a partir del siglo XVIII. Tenemos definido \\
ese proceso educativo contemporáneo más amplio, \\
como "politización del femenino y de la maternidad" \\
(MEYER, 2003), un proceso que, por extensión, incluye \\
la "politización del cuerpo embarazado" (SCHWENGBR, \\
2006 ). Para hacer esa discusión, examinamos la re- \\
vista Pais e Filhos, en el periodo de 1968 a 2004, \\
utilizándonos de las estrategias metodo-lógicas del \\
análisis de discurso. Del resultado de las análisis loca- \\
lizo un movimiento que permite visualizar la emergencia \\
de una lógica, según la cual la educación de los cuerpos \\
embarazados se intensifica, por medio de las prácticas \\
corporales, construyendo diferentes posiciones de \\
sujeto: la de madre deportiva (que cuida y se cuida); \\
la que abriga y protege; la cariñosa y protectora, respon- \\
sable por el hijo perfecto. \\
Palabras clave: Cuerpo humano. Identidad de género. \\
Mujeres embarazadas. Medios de comunicación de \\
masas.
\end{tabular}

\section{REFERÊNCIAS}

BADINTER, E. Um amor conquistado: o mito do amor materno. Rio de Janeiro: Nova Fronteira, 1985.

CASTELLS, M. A era da informação: economia, sociedade e cultura, o poder da identidade. São Paulo: Paz e Terra, 1999.

COELHO, N. Ser mãe é padecer num paraíso! Disponível em: http://www.amor emversoeprosa.com/cirandas/442cirandadasmaes.htm. Acesso em 14 setembro 2006.

CORREAA, M. V. Novas tecnologias reprodutivas: limites da biologia ou biologia dos limites. Rio de Janeiro: Ed. UERJ, 2001.

COSTA, J. F. Ordem médica e norma familiar. Rio de Janeiro: Graal,1979.

DAOILO, J. A cultura do corpo. São Paulo: Papirus, 2004.

FELIPE, J. Governando os corpos femininos. Labrys, n. 4, jul./dez. 2003.

Movimento, Porto Alegre, v. 15, n. 03, p. 209-232, julho/setembro de 2009. 
FISCHER, R. M. B. Mídia e educação da mulher: modos de enunciar o feminino na TV. In: FUNK, S. WIDHOLZER, N. (Org.). Gênero em discursos da mídia. Florianópolis: Ed Mulheres, 2005

FOUCAULT, M. A ética do cuidado de si como prática da liberdade. In: Ética, sexualidade, política: ditos e escritos. Rio de Janeiro: Forense, 2004.

Em defesa da sociedade: cursos do College de France (1975-1976). São Paulo: Martins Fontes, 1999.

Vigiar e punir: nascimento da prisão. Petrópolis: Vozes, 1979

FRAGA, A. B. Exercício da informação: governo dos corpos no mercado da vida ativa. 2005. Tese (Doutorado em Educação) - Faculdade de Educação, Universidade Federal do Rio Grande do Sul. Porto Alegre, 2005.

GHIRALDELLI, P. O corpo. São Paulo: Ática, 2008.

GOELLNER, S. V. O esporte e a espetacularização dos corpos femininos. Labrys, n. 4, ago./dez., 2003.

- Mulher e esporte no Brasil: fragmento de uma história generificada. In: $\mathbf{O}$ mundo psicossocial da mulher no esporte, comportamento, gênero, desempenho. São Paulo: Aleph, 2004.

LIPOVETSKY, G. A sociedade pós-moralista: o crepúsculo do dever e a ética indolor dos novos tempos demcráticos. Tradução Ara Braio. São Paulo: Manole, 2006.

LUPTON, D. Risk and the ontoloy pregram. In: LUPTON, D. Risk and sociocultural theory: new directions and perspectives. Cambridge/UK: University Press, 1999.

MEYER, D. Direitos reprodutivos e educação para o exercício da cidadania reprodutiva: perspectivas e desafios. In: FONSECA, C.; TERTO, V.; ALVES, C., (Org.). Antropologia, diversidade e direitos humanos: diálogos interdisciplinares Porto Alegre: UFRGS, 2004.

As mamas como constituintes da maternidade: uma história do passado? Educação e Realidade, Porto Alegre, v. 25, n. 2, jul./dez., 2000.

A politização contemporânea da modernidade. Gênero: núcleo transdisciplinar de estudos de gênero, Niterói, v. 6, n. 1, 2006.

MIRA, M. C. O leitor e a banca de revistas: a segmentação da cultura no Século XX. São Paulo: Olho D’Água/FAPESP, 2001.

PAIS \& FILHOS. São Paulo: Bloch e Manchete, anos 1-37. (Coleção). Disponível em http://www.revistapaisefilhos.terra.com.br. Acesso em: 2003; 2004; 2005; 2006

POCIELLO, C. Os desafios da leveza e as praticas corporais em mutação. In:SANT'ANNA, Denise B. (Org). Políticas do corpo. São Paulo: Estação liberdade, 1995.

Movimento, Porto Alegre, v. 15, n. 03, p. 209-232, julho/setembro de 2009. 


\section{Antifos Origimais}

Maria Simone Vione Schwengber

SANT'ANNA, D. B. Educação física e história. In: CARVALHO, Y. Educação física e ciências humanas. São Paulo: Hucitec, 2001.

SCAVONE, L. Dar e cuidar da vida: feminismo e ciências sociais. São Paulo: UNESP, 2004.

SCHPUN, M. R. Beleza em jogo: cultura física e comportamento em São Paulo nos Anos 20. São Paulo: Senac, 1999.

SILVA, T. T. Nunca fomos humanos: nos rastros dos sujeitos. Belo Horizonte: Autêntica, 2001.

SOARES, C. Arquitetura e educação do corpo: notas indicadas. Revista do Núcleo de Desenvolvimento da Criatividade da UNICAMP, Campinas, v. 10, n. 1, 2004.

Cultura de Movimento. Revista do SESC: Corpo Prazer e Movimento, São Paulo, 2003.

SOARES, C. Pedagogias do corpo: higiene, ginástica, esporte. In: RAGO, M.; VEIGA NETO. As figuras de Foucault. Belo Horizonte: Contexto, 2006 (no prelo).

. Práticas corporais: invenção de pedagogias? In: SILVA, A. M.; DAMIANI, I. R. (Org.). Práticas corporais. Florianópolis: Naemblu Ciência e Arte, 2005.

VAZ, P. R. G. Corpo e risco: fórum media. Disponível em: http://www.eco.ufrj.br/ paulovaz/textos/corpoerisc.pdf. Acesso em: 06 março 2006.

VIGARELLO, G.; SANT'ANNA, D. (entrevista). O corpo inscrito na história: imagens de um arquivo vivo. Projeto História, São Paulo, n. 21, 2002.

VIRILIO, P. Os motores da história. In: ARAUJO, Hermes Reis (Org.). Tecnociência e cultura: ensaios sobre o tempo presente. São Paulo: Estação Liberdade, 1998.

Recebido em: 25.08.2008

Aprovado em: 11.11. 2008

Movimento, Porto Alegre, v. 15, n. 03, p. 209-232, julho/setembro de 2009. 